www.jmscr.igmpublication.org

Impact Factor 5.84

Index Copernicus Value: 83.27

ISSN (e)-2347-176x ISSN (p) 2455-0450

crossref DOI: https://dx.doi.org/10.18535/jmscr/v5i7.205

Journal Of Medical Science And Clinical Research

IGM Publication

An Official Publication of IGM Publication

\title{
MRI Characterisation of Focal Liver Lesions- A Tertiary Care Centre Study
}

\author{
Authors
}

\section{Ajitha.J $S^{1}$, Preetha $S^{2^{*}}$, Devarajan $E^{3}$}

${ }^{1}$ Assistant Professor, Dept of Radiodiagnosis, Govt Medical College, Thiruvananthapuram, Kerala, India

${ }^{2}$ Associate Professor, Dept Of General Surgery, Govt Medical College, Thiruvananthapuram, Kerala, India

${ }^{3}$ Professor, Department of Radiodiagnosis, Government Medical College, Manjeri, Kerala, India Corresponding Author*

\section{Preetha S}

Associate Professor, Dept of General Surgery, Govt Medical College, Thiruvananthapuram,

Kerala, India 695011

Email: arulakam69@gmailcom

\begin{abstract}
Back ground: The role of MRI is more rewarding as it is known that MRI details of soft tissue is superior than CT or any other imaging modalities and this quality is utilized in the evaluation of focal liver lesions, apart from the otheradvantages of MRI like, less risk of radiation, safe in renal disease, and being non invasive in the delineation of hepatic segmental anatomy and vascular anatomy and biliary anatomy and the sensitivity in detecting small lesions and the extent of lesions. Equivocal characteristics in an USS/CECT are better delineated by MRI. It also has a wide range of contrast enhancement than other technique and the diagnostic accuracy has increased by contrast enhanced MRI. The tumor vascularity and its enhancement pattern is improved by Fast Breath Holding Sequences using Gadolinium which is not possible on CT or USS.

Methods: A prospective study was conducted in the dept. of Radiodiagnosis, MCH, during the period of 2013 to 2016 on patients undergoing MR imaging of liver for characterisation of liver lesions.

Results: MRI has specific enhancement pattern for each focal liver lesions by which the focal lesions are characterized more accurately. The diagnostic accuracy of the MRI characterization of focal lesions in our study were confirmed histopathologically or by FNA except vascular lesions.

Conclusion: The value of contrast enhanced MRI in the evaluation of focal hepatic neoplasm is proved in this study. It is safe, lacks ionizing radiation and is highly sensitive and specific. Characterisation of focal liver lesion is very limited in ultrasound, which is the most commonly employed as a screening modality, mainly for lesion detection in the majority of cases.

Keywords: MRI, CT, focal liver lesions.
\end{abstract}

\section{INTRODUCTION}

Liver is the largest organ in the abdomen, having a number of important functions. The characterization of focal liver lesions is challenging both for the clinician and for the radiologists. Imaging of the liver can be accomplished by a number of modalities like plain radiographs, ultrasound, CT, radio - isotope 
studies, MRI and invasive procedures like angiography, percutaneous transhepatic cholangiography and endoscopic retrograde cholangiography. Plain radiograph of the abdomen is only of limited value and may show enlargement of liver, calcification of hydatid cyst, other calcified granulomas, or air -fluid level in pyogenic abscess. US is safe, simple, non invasive, cheap, yet effective method which is able to pick up a number of abnormalities of the liver, bile ducts, gall bladder and other organs. CT has been widely used for evaluating liver problems but it uses ionising radiation and radiation burden is further increased with multiphase imaging. Moreover, the use of iodinated contrast media increases the risk of renal insufficiency in patients with previously existing renal impairement. Radio- isotope scanning using technetium $99 \mathrm{P}^{\mathrm{mP}}\left(99 \mathrm{P}^{\mathrm{mP}} \mathrm{Tc}\right)$ is another imaging modality. Scintigraphy tends to be non - specific and almost always needs to be supplemented by other imaging modalities. Small tumors less than $20 \mathrm{mms}$ and deep seated tumors may be missed on scintigraphy.

Thus we see that a number of imaging modalities and biochemical investigations are available to us for evaluation of a patient with a suspected hepatic problem.

MRI is more sensitive than CT or ultrasound in detecting small lesions and is also more specific in the characterisation of various pathologies. The correct delineation and extent of the lesion can be better assessed by MRI. Liver MRI is best used in problem cases where US or CT findings are equivocal.MRI has a wide range of contrast mechanisms than other imaging techniques. Although primarly used for lesion detection and characterization, the biliary system anatomy and hepatic vascular patency can also be assessed during the same examination. MR coronal imaging also has the advantage of better evaluation of segmental anatomy and hepatic venous anatomy.
Inspite of a variable specificity, contrast enhanced MR imaging of the liver can improve diagnostic accuracy. The tumour vascularity and its enhancing pattern can be obtained by fast breathhold sequences using gadolinium. Gradient echo sequences are specially useful to detect tomour thrombus in portal vein and IVC. MRI helps to differentiate hypervascular malignant lesions as HCC or metastasis from hypervascular benign tumours as adenoma and FNH. It also helps to differentiate HCC, metastasis and hemangioma in problematic cases.

The development of breath holding imaging techniques and the use of oral, iv and liver specific contrast media has led to the emerging superiority of MRI over other techniques in the evaluation of focal liver lesions. Specific MRI procedures can be designed to exploit differences in physiochemical and physiological properties of different tissues as well as their anatomical features.

MRI offers 'one-stop shopping' for assessing the local staging and resect ability of liver tumours. Segmental localization is largely defined by the major intrahepatic branches of the portal vein and by the hepatic veins, which are well shown on dynamic gadolinium enhanced images. The extrahepatic portal venous system can be demonstrated by the same technique or by MRA.

The ability to aquire MR images in any plane facilitates the demonstration of surgical anatomy, particularly of the portal system, the extrahepatic bile ducts and the IVC. Combining gadolinium and SPIO enhancement maximises the ability to detect and characterise liver lesions. By analyzing the qualitative and quantitative lesion characteristics in CEMRI, a radiological imaging much closer to the histopathological diagnosis can be made.

A focal liver lesion is by definition a discrete abnormality arising within the liver. Detection of tumor, differential diagnosis of individual nodules and mapping anatomic extensions are routinely required. Related and unrelated conditions like hemangiomas, fatty deposits may co-exist with 
malignant lesions, further complicating evaluation. MRI is very sensitive as a 'dedicated liver examination' in such cases.

With this background, this study has been carried out to characterize focal liver lesions by MRI.

Focal solitary liver lesions could be benign or malignant.

\section{AIMS AND OBJECTIVES}

- To evaluate the characteristics of focal liver lesions.

- To assess the extent of the lesions with respect to segmental anatomy of the liver for considering resectability.

- To compare and correlate the radiological diagnosis with the final histopathological diagnosis.

\section{MATERIALS AND METHODS}

A prospective study was conducted in the dpt. of Radiodiagnosis , MCH during the period of 20132016 on patients undergoing MR imaging of liver for characterisation of liver lesions.

\section{SELECTION CRITERIA}

- Inclusion criteria

All those patients send to the department for MRI for liver lesions.

\section{- Exclusion criteria}

Patients with contraindications for MRI

\section{Technique used}

MRI of the liver was performed by GE HDxt Signa 1.5 Tesla MR scanner with 8 channel phased array body surface coil.

\section{Srquences used}

TIW axial, T2W FS, Dual echo sequences, Heavily T2WI by increasing TE (60-180ms), LAVA Sequence after administration of $0.2 \mathrm{ml} /$ $\mathrm{Kg}$ body weight of Gadolinium.( dyanamic study in early arterial, late arterial, portal venous, equilibrium and delayed phases).

\section{METHODOLOGY IN BRIEF}

Thirty cases were evaluated for this study. The criteria evaluated were

1.N0. of lesions, 2.location of lesion,

3.size of largest lesion

4.margin of the lesion-,

-well-defined,.lobulated,irregular,.ill-defined

5.internal structure-

-water content, fat content, presence of blood, nonspecific

6.T1 signal intensity-

-hypointense, hyperintense, isointense,

heterogeneous

7.T2 signal intensity-

-hypointense,

hyperintense,

isointense, heterogeneous

8.heavily T2WI-

-increase in signal intensity, decrease in signal intensity ,no change

9.enhancement pattern

1.no enhancement

2.arterial phase enhancing

3.ring enhancement

4.nodule within nodule enhancement

5.peripheral washout

6.rim enhancement

7.delayed enhancement

8.peripheral globular enhancement with centripetal fill-in and persisting in delayed images

9.heterogeneous enhancement

\section{OBSERVATIONS AND RESULTS}

In this study 30 cases of hepatic focal lesions were evaluated with MRI and correlated with FNAC. Age of the included patients ranged from 27 -80 yrs.

Based on MRI characteristics the focal lesions were categorized as metastasis $(26.7 \%)$, hepatocellular carcinoma (20\%), intrahepatic cholangiocarcinoma (10\%, hemangioma $(13.3 \%)$, biliary cystadenoma (6.7\%), simple cysts $(6.7 \%)$, regenerating and dysplastic nodules $(6.7 \%)$, pyogenic abscess (3.3\%), hydatid cyst $(3.3 \%)$, and polycystic kidney disease with hepatic cyst $(3.3 \%)$ 


\section{MRI FINDINGS}

\section{Metastasis}

Out of 30 cases, diagnosis of metastasis were made on 8 cases based on contrast enhancement pattern.

Unenhanced MRI Findings

- Multiple lesions (6 cases)

- Solitary lesion ( 1 case)

- Double lesion (1 case)

- Cirhhotic liver (nil)

- Non cirrhotic liver (8 cases)

- Iso intense in $\mathrm{T} 1$ and hyperintense in T2WI(4cases)

- Hypointense in T1 and hyperintense in T2WI (1case)

- Hypointense in heavily T2WI (3 cases)

- Irregular margins(6 cases)

\section{CEMRI findings}

\section{Enhancement pattern}

- Peripheral washout (5 cases)

- heterogeneous enhancement ( 1 case)

The diagnosis of metastasis was confirmed on 7 out of these 8 cases based on FNAC. One case turned out to be HCC on FNAC.

Hepatocellular Carcinoma

Out of 30 cases, diagnosis of hepatocellular carcinoma were made on 6 cases based on contrast enhancement pattern.

Unenhanced MRI Findings

Solitary lesion ( 3 cases).

Multiple lesions ( 3 cases).

Isointense in T1W1, Hyperintense in T2WI (3 cases).

Hypointense in T1W1, Hyperintense in T2WI (3 cases )

Irregular margin ( 3 cases)

Ill-defined margin ( 3 case)

Internal hemorrhage (1case)

Portal and hepatic vein invasion ( 2 cases)

Cirrhotic liver (3 cases)

Non cirrhotic liver (3cases)

\section{CEMRI}

\section{Enhancement pattern}

_ Heterogeneous enhancement during the arterial phase and subsequent phases ( 5 cases) -nodule within nodule enhancement (1case)

The diagnosis of hepatocellular carcinoma was confirmed on 5 out of these 6 cases based on FNAC. One case turned out to be metastasis on FNAC.

Hilar Chalangiocarcinoma

Unenhanced MRI

Hypointense in $\mathrm{T} 1$ and hyperintense in $\mathrm{T} 2 \mathrm{~W} 1$ (3cases).

Irregular margins ( 3 cases)

\section{CEMRI}

Delayed enhancement (7 -8 mts) (3cases)

Post operative biopsy confirmed the diagnosis.

Hemangioma:Out of 30 cases, diagnosis of hemangioma were made on 4 cases based on contrast enhancement pattern and morphology.

Unenhanced MRI Findings

-lobulated lesions (4cases)

-solitary lesion( 2cases)

-multiple lesions ( 2 cases)

-hypointense in $\mathrm{T} 1$ and hyper intense in $\mathrm{T} 2 \mathrm{WI}(4$ case)

-hyperintense in heavily $\mathrm{T} 2 \mathrm{WI}(3$ cases $)$

-no change in heavily T2WI (1 case)

\section{CEMRI}

Enhancement pattern

- Type2 enhancement ( 2 cases)

-Type 3 enhancement ( 2 cases)

All cases were followed up after 6 months by USG. All cases show no significant change in size.

Biliary Cystadenoma

Unenhanced MRI

Large well-defined lesion with thick irregular walls (3cases)

Hypointense in $\mathrm{T} 1$ and hyperintense in T2W1(3cases) 


\section{CEMRI}

Nonenhancing cystic component with thick enhancing wall (3cases)

Post operative biopsy confirmed the diagnosis.

Simple cyst

Unenhanced MRI

-well-defined cystic lesion (2cases)

-hypointense in T1 and hyperintense in T2WI (2 cases)

-no increase in signal intensity in heavily T2WI ( 2 cases)

\section{CEMRI}

No enhancement (2cases)

The cases were followed up by USG. Showed cystic lesion with no change in size.

Hydatid cyst (1 case)

Unenhanced MRI

Well-defined, hypointense lesion in $\mathrm{T} 1$ and hyperintense in T2WI( 1 case $)$

No change in heavily T2WI(1 case)

\section{CEMRI}

Rim enhancement $(1$ case $)$

Pyogenic liver abscess
Well-defined, hypointense in $\mathrm{T} 1$ and hyperintense in T2WI (1)

No change in heavily T2WI(1 case)

Diffusion restriction (1case)

\section{CEMRI}

Rim enhancement (1)

Regenerating nodule

Unenhanced MRI

Multiple small lesions isointense in T1 and T2WI

No increase in signal in heavily T2WI

\section{CEMRI}

No enhancement

Dysplastic nodule

Hyper intense in $\mathrm{T} 1$ and hypointense in $\mathrm{T} 2 \mathrm{~W} 1$

No increase in signal in heavily T2WI

\section{CEMRI}

No enhancement

PCKD with hepatic cysts ( 1 case)

-Multiple cysts of varying sizes in both lobes of liver and in both kidneys

-hypointense in T1WI and hyperintense in T2WI -no enhancement

\section{Descriptive Statistics}

\begin{tabular}{|l|c|c|c|c|c|c|}
\hline & N & Range & Minimum & Maximum & Mean & Std. Deviation \\
\hline Age & 30 & 53 & 27 & 80 & 52.57 & 13.325 \\
size of largest lesion & 30 & 2 & 1 & 3 & 2.30 & .702 \\
Valid N (listwise) & 30 & & & & & \\
\hline
\end{tabular}

\begin{tabular}{|c|c|c|c|c|c|}
\hline & & Frequency & Percent & Valid Percent & $\begin{array}{c}\text { Cumulative } \\
\text { Percent }\end{array}$ \\
\hline \multirow[t]{7}{*}{ Valid } & $11-20$ & 1 & 3.3 & 3.3 & 3.3 \\
\hline & $21-30$ & 7 & 23.3 & 23.3 & 26.7 \\
\hline & $31-40$ & 7 & 23.3 & 23.3 & 50.0 \\
\hline & $41-50$ & 6 & 20.0 & 20.0 & 70.0 \\
\hline & $51-60$ & 7 & 23.3 & 23.3 & 93.3 \\
\hline & $>61$ & 2 & 6.7 & 6.7 & 100.0 \\
\hline & Total & 30 & 100.0 & 100.0 & \\
\hline
\end{tabular}

SEX
\begin{tabular}{|ll|c|c|c|c|}
\hline & & & & \\
& & Frequency & Percent & Valid Percent & $\begin{array}{c}\text { Cumulative } \\
\text { Percent }\end{array}$ \\
\hline Valid & F & 10 & 33.3 & 33.3 & 33.3 \\
& M & 20 & 66.7 & 66.7 & 100.0 \\
& Total & 30 & 100.0 & 100.0 & \\
\hline
\end{tabular}


Distribution of malignant lesions according to age

\begin{tabular}{|l|c|c|c|}
\hline Age Group & Metastasis & HCC & Intrahepatic CC \\
\hline$<30 \mathrm{yrs}$ & 0 & 1 & \\
\hline $31-40 \mathrm{yrs}$ & 0 & 2 & 1 \\
\hline $41-50 \mathrm{yrs}$ & 3 & 1 & 0 \\
\hline $51-60 \mathrm{yrs}$ & 3 & 0 & 1 \\
\hline $61-70 \mathrm{yrs}$ & 1 & 1 & 1 \\
\hline $71-80 \mathrm{yrs}$ & 1 & 1 & 0 \\
\hline
\end{tabular}

Distribution of benign lesions according to age

\begin{tabular}{|l|c|c|c|c|c|c|c|}
\hline $\begin{array}{l}\text { Age } \\
\text { Group }\end{array}$ & hemangioma & $\begin{array}{c}\text { Biliary } \\
\text { cystadenoma }\end{array}$ & $\begin{array}{c}\text { Simple } \\
\text { cyst }\end{array}$ & $\begin{array}{c}\text { Pyogenic } \\
\text { abscess }\end{array}$ & $\begin{array}{c}\text { Hydatid } \\
\text { cyst }\end{array}$ & $\begin{array}{c}\text { Regen \& } \\
\text { dyspl }\end{array}$ & $\begin{array}{c}\text { PCKD with hepatic } \\
\text { cyst }\end{array}$ \\
\hline$<30$ yrs & 0 & 0 & 0 & 0 & 0 & 0 & 0 \\
\hline $31-40 y r s$ & 1 & 0 & 1 & 1 & 0 & 0 & 1 \\
\hline $41-50 y r s$ & 2 & 1 & 0 & 0 & 1 & 0 & 0 \\
\hline $51-60 y r s$ & 0 & 0 & 1 & 0 & 0 & 1 & 0 \\
\hline $61-70 y r s$ & 1 & 1 & 0 & 0 & 0 & 1 & 0 \\
\hline $71-80 y r s$ & 0 & 0 & 0 & 0 & 0 & 0 & 0 \\
\hline
\end{tabular}

status of liver

\begin{tabular}{|c|c|c|c|c|c|}
\hline & & Frequency & Percent & Valid Percent & $\begin{array}{c}\text { Cumulative } \\
\text { Percent }\end{array}$ \\
\hline Valid & $\begin{array}{l}\text { CIRRHOTIC } \\
\text { non-CIRRHOTIC } \\
\text { Total }\end{array}$ & $\begin{array}{c}6 \\
24 \\
30\end{array}$ & $\begin{array}{c}20.0 \\
80.0 \\
100.0\end{array}$ & $\begin{array}{c}20.0 \\
80.0 \\
100.0\end{array}$ & $\begin{array}{c}20.0 \\
100.0\end{array}$ \\
\hline
\end{tabular}

No.of lesions

\begin{tabular}{|ll|c|c|c|c|}
\hline & & & & Cumulative \\
& & Frequency & Percent & Valid Percent & Percent \\
\hline Valid & DOUBLE & 4 & 13.3 & 13.3 & 13.3 \\
& MULTIPLE & 17 & 56.7 & 56.7 & 70.0 \\
& SINGLE & 9 & 30.0 & 30.0 & 100.0 \\
& Total & 30 & 100.0 & 100.0 & \\
\hline
\end{tabular}

\section{Location}

\begin{tabular}{|ll|c|c|c|c|}
\hline & & & & Cumulative \\
Valid & Both lobe & 15 & 50.0 & 50.0 & 50.0 \\
& L lobe & 3 & 10.0 & 10.0 & 60.0 \\
& R lobe & 12 & 40.0 & 40.0 & 100.0 \\
& Total & 30 & 100.0 & 100.0 & \\
\hline
\end{tabular}

Margin

\begin{tabular}{|cl|c|c|c|c|}
\hline & Frequency & Percent & Valid Percent & $\begin{array}{c}\text { Cumulative } \\
\text { Percent }\end{array}$ \\
\hline Valid & WELL-DEFINED & 9 & 30.0 & 30.0 & 30.0 \\
& LOBULATED & 10 & 33.3 & 33.3 & 63.3 \\
& IRREGULAR & 8 & 26.7 & 26.7 & 90.0 \\
ILL-DEFINED & 3 & 10.0 & 10.0 & 100.0 \\
Total & 30 & 100.0 & 100.0 & \\
\hline
\end{tabular}


Internal structure

\begin{tabular}{|l|c|c|c|c|c|}
\hline & Frequency & Percent & Valid Percent & Cumulative Percent & \\
\hline Valid & WATER CONTENT & 8 & 26.7 & 26.7 & 26.7 \\
& PRESENCE OF BLOOD & 1 & 3.3 & 3.3 & 30.0 \\
& NONSPECIFIC & 21 & 70.0 & 70.0 & 100.0 \\
& Total & 30 & 100.0 & 100.0 & \\
\hline
\end{tabular}

\begin{tabular}{|c|c|c|c|c|c|}
\hline & & Frequency & Percent & Valid Percent & $\begin{array}{c}\text { Cumulative } \\
\text { Percent }\end{array}$ \\
\hline \multirow[t]{3}{*}{ Valid } & HYPOINTENSE & 24 & 80.0 & \multirow{5}{*}{$\begin{array}{c}82.8 \\
17.2 \\
100.0\end{array}$} & \multirow{5}{*}{$\begin{array}{c}82.8 \\
100.0\end{array}$} \\
\hline & ISOINTENSE & 5 & 16.7 & & \\
\hline & Total & 29 & 96.7 & & \\
\hline Missing & System & 1 & 3.3 & & \\
\hline Total & & 30 & 100.0 & & \\
\hline
\end{tabular}

\section{T2signal}

\begin{tabular}{|ll|c|c|c|c|}
\hline & & Frequency & Percent & Valid Percent & $\begin{array}{c}\text { Cumulative } \\
\text { Percent }\end{array}$ \\
\hline Valid & HYPOINTENSE & 1 & 3.3 & 3.4 & 3.4 \\
& HYPERINTENSE & 27 & 90.0 & 93.1 & 96.6 \\
& ISOINTENSE & 1 & 3.3 & 3.4 & 100.0 \\
& Total & 29 & 96.7 & 100.0 & \\
Missing & System & 1 & 3.3 & & \\
Total & & 30 & 100.0 & & \\
\hline
\end{tabular}

\section{Heavily T2WI}

\begin{tabular}{|c|c|c|c|c|c|c|}
\hline & & & Frequency & Percent & Valid Percent & $\begin{array}{c}\text { Cumulative } \\
\text { Percent }\end{array}$ \\
\hline Valid & $\begin{array}{ll}\text { INCREASE } & \text { II } \\
\text { INTENSITYY }\end{array}$ & SIGNAL & 10 & 33.3 & 47.6 & 47.6 \\
\hline & $\begin{array}{l}\text { DECREASE } \\
\text { INTENSITY }\end{array}$ & SIGNAL & 2 & 6.7 & 9.5 & 57.1 \\
\hline & NO CHANGE & & 9 & 30.0 & 42.9 & 100.0 \\
\hline & Total & & 21 & 70.0 & 100.0 & \\
\hline Missing & System & & 9 & 30.0 & & \\
\hline Total & & & 30 & 100.0 & & \\
\hline
\end{tabular}

\section{Enhancement}

\begin{tabular}{|c|c|c|c|c|c|}
\hline & & Frequency & Percent & Valid Percent & $\begin{array}{c}\text { Cumulative } \\
\text { Percent }\end{array}$ \\
\hline \multirow[t]{5}{*}{ Valid } & $\begin{array}{lll}\text { NO } & \text { 1INCREASE } & \text { IN } \\
\text { SIGNAL INTENSITY } & \end{array}$ & 4 & 13.3 & 14.3 & 14.3 \\
\hline & NO CHANGE & 4 & 13.3 & 14.3 & 28.6 \\
\hline & 5 & 3 & 10.0 & 10.7 & 39.3 \\
\hline & 6 & 1 & 3.3 & 3.6 & 42.9 \\
\hline & $\begin{array}{l}\text { DELAYED } \\
\text { ENHANCEMENT }\end{array}$ & 1 & 3.3 & 3.6 & 46.4 \\
\hline
\end{tabular}




\begin{tabular}{|c|c|c|c|c|c|}
\hline $\begin{array}{l}\text { Missing } \\
\text { Total } \\
\text { Totat }\end{array}$ & $\begin{array}{l}\text { PERIPHERAL } \\
\text { GLOBULAR } \\
\text { ENHANCEMENT WITH } \\
\text { CENTRIPETAL FILL-IN } \\
\text { AND PERSISTING IN } \\
\text { DELAYED IMAGES } \\
9 \\
\text { Total } \\
\text { System }\end{array}$ & $\begin{array}{c}6 \\
28 \\
2 \\
30\end{array}$ & $\begin{array}{c}20.0 \\
93.3 \\
6.7 \\
100.0\end{array}$ & $\begin{array}{c}21.4 \\
100.0\end{array}$ & 100.0 \\
\hline
\end{tabular}

size of largest lesion

\begin{tabular}{|cc|c|c|c|c|}
\hline & & Frequency & Percent & Valid Percent & $\begin{array}{c}\text { Cumulative } \\
\text { Percent }\end{array}$ \\
\hline Valid & $1-2 \mathrm{~cm}$ & 4 & 13.3 & 13.3 & 13.3 \\
& $2.2-5 \mathrm{~cm}$ & 13 & 43.3 & 43.3 & 56.7 \\
& $>5 \mathrm{~cm}$ & 13 & 43.3 & 43.3 & 100.0 \\
& Total & 30 & 100.0 & 100.0 & \\
\hline
\end{tabular}

MRI diagnosis

\begin{tabular}{|ll|c|c|c|c|}
\hline & & Frequency & Percent & Valid Percent & $\begin{array}{c}\text { Cumulative } \\
\text { Percent }\end{array}$ \\
\hline Valid & 1 & 3 & 10.0 & 10.7 & 10.7 \\
& 2 & 9 & 30.0 & 32.1 & 42.9 \\
& 3 & 3 & 10.0 & 10.7 & 53.6 \\
& 4 & 3 & 10.0 & 10.7 & 64.3 \\
& 5 & 1 & 3.3 & 3.6 & 67.9 \\
6 & 1 & 3.3 & 3.6 & 71.4 \\
& 7 & 1 & 3.3 & 3.6 & 75.0 \\
& 8 & 1 & 3.3 & 3.6 & 78.6 \\
& 9 & 2 & 6.7 & 7.1 & 85.7 \\
& 11 & 1 & 3.3 & 3.6 & 89.3 \\
& 12 & 1 & 3.3 & 3.6 & 92.9 \\
& 13 & 1 & 3.3 & 3.6 & 96.4 \\
& 14 & 1 & 3.3 & 3.6 & 100.0 \\
Missing & Total & 28 & 93.3 & 100.0 & \\
Total & 2 & 6.7 & & \\
\hline
\end{tabular}

No. Of malignant lesions-17

\begin{tabular}{|l|c|c|c|c|}
\hline & True $+\mathrm{ve}$ & False+ve & false-ve & True $-\mathrm{ve}$ \\
\hline HCC & 5 & 1 & 1 & 9 \\
\hline Metastasis & 7 & 1 & 1 & 9 \\
\hline Hilar cholangio ca & 3 & 0 & 0 & 14 \\
\hline
\end{tabular}

\begin{tabular}{|l|c|c|c|c|}
\hline & Sensitivity \% & Specificity\% & $\begin{array}{c}\text { Positive predictive } \\
\text { value } \%\end{array}$ & $\begin{array}{c}\text { Negative } \\
\text { predictive value } \%\end{array}$ \\
\hline HCC & 83.33 & 90 & 83.33 & 90 \\
\hline Metastasis & 87.5 & 90 & 87.33 & 90 \\
\hline Hilar cholangio ca & 100 & 100 & 100 & 100 \\
\hline
\end{tabular}




\section{DISCUSSION}

Unenhanced and contrast enhanced MRI evaluation of 30 focal hepatic lesions were performed by GE HDxt Signa 1.5 Tesla MR scanner with 8 channel phased array body surface coil.

The MR evaluation and diagnosis were compared with FNAC report.

The age group of the patients ranged from 27 to 80 years. The male to female ratio was $2: 1$

Eight cases were diagnosed as metastasis, six cases as hepatocellular carcinoma, three cases as hilar cholangiocarcinoma, four cases as hemangioma, two cases as biliary cystadenoma, two cases as simple cyst, two cases as regenerating and dysplastic nodules in cirrhosis liver ,one case each as hydatid cyst, pyogenic abscess and polycystic kidney disease with hepatic cysts, based on morphology and enhancement pattern.

Out of the eight MRI diagnosed cases of metastasis, seven cases were proved to be metastasis and one case turned out to be hepatocellular carcinoma on FNAC. The sensitivity and specificity of CEMRI in diagnosis of metastasis were $87.5 \%$ and $90 \%$ respectively.

All the lesions were hypointense on T1WI, hyperintense on T2WI relative to the normal liver. Five lesions showed peripheral washout on delayed phase imaging. Some enhancement characteristics, such as an early ring enhancement and peripheral washout, are considered specific to metastases and allow differentiation of metastases from benign liver lesions such as cysts or hemangiomas. These enhancement patterns were present in our study.

The other pattern which was dominant in metastasis was the peripheral continuous hypervascular rim on late arterial phase ( 3 out of 8 cases). Nino Murcia et al analysed arterial phase enhancement pattern of hepatic tumors and proved that the peripheral continuous hypervascular rim pattern, relatively specific for either a metastasis or abscess. But the clinical context often is quite different for these two entities.
A false positive diagnosis of metastasis was done in one case, which turned out to be hepatocellular carcinoma on FNAC. Large hepatocellular carcinoma receiving blood supply from portal venous system may appear hypointense on arterial phase instead of the marked enhancement in this phase, which is typical of the lesion. This reason may explain one false positive case.

Out of the 6 cases in which hepatocellular carcinoma was given as diagnosis based on MRI, 5 cases were proved the same by FNAC. 1case turned out to be metastasis. On both T1- and T2weighted images, the mosaic pattern appears as areas of variable signal intensity, whereas on gadolinium-enhanced images, the lesions enhance in a heterogeneous pattern during the arterial phase and subsequent phases.

Arterial hypervascularization is part of the noninvasive criteria to establish HCC diagnosis. Neovascularity was seen in 5 cases of our study and one case did not show neovascularity which turned out to be metastasis. Among the characteristic features of HCC is a propensity to invade the portal vein and less frequently the hepatic veins or bile ducts. In our study, 2 out of 6 cases showed portal and hepatic vein invasion.

Hecht et al. evaluated signal characteristics in dynamic $\mathrm{T} 1 \mathrm{w}$ sequences as stand-alone sequences for diagnosis of HCC

Lauenstein et al. evaluated contrast-enhanced MRI for 115 patients before liver transplantation, retrospectively. Thirty-six HCCs in 27 patients were histopathologically evaluated. MRI showed a lesion-based sensitivity of $77.8 \%$. Although all HCCs larger than $2 \mathrm{~cm}$ were depicted with MRI, only 10 of $18 \mathrm{HCCs}$ smaller than $2 \mathrm{~cm}$ were correctly diagnosed. The authors concluded that contrast-enhanced MRI could none-the-less be considered the primary diagnostic method for the detection and characterization of HCCs $2 \mathrm{~cm}$ or larger. However, in comparison with CT \&ultrasound, MRI is superior in detecting lesions smaller than $2 \mathrm{~cm}$.

The enhancement pattern criteria for HCC in this study was heterogeneous enhancement pattern in 
most of the lesions and one case showed nodule within nodule enhancement.

MRI is highly sensitive and specific in this study in diagnosing hemangioma, biliary cystadenoma, hilar cholangiocarcinoma, pyogenic abscess, regenerative and dysplastic nodules. Cholangiocarcinomas tend to have increased contrast enhancement on delayed images.

Hemangiomas have specific morphologic appearance and enhancement pattern. On T2weighted images, however, hemangiomas demonstrate a markedly bright signal (Brown et al., 1991). The signal intensity is characteristically of the same magnitude as that of the CSF (Wittenberg et al., 1988). The highly specific feature of hemangiomas is their contrast enhancement pattern (Mitchell et al., 1994). On unenhanced T1-weighted images, hemangiomas are usually well-defined, lobulated and hypointense. On unenhanced T2-weighted images, hemangiomas appear markedly hyperintense .Due to their very long T2 time, they retain signal on heavily T2WI (TE > $120 \mathrm{~ms}$ )-'light bulb sign ${ }^{, 31,32}$.With extracellular, gadolinium chelateenhanced MR imaging, hemangiomas show three types of enhancement patterns, depending on the size and histological subtype. Small lesions (1-2 $\mathrm{cm})$ show immediate and complete enhancement in the early phase (Type 1) with persistent enhancement in the delayed phase. Medium-sized $(1-5 \mathrm{~cm})$ hemangiomas, the most common, show peripheral nodular enhancement, with progressive centripetal enhancement and fill-in on equilibrium phase images (Type II). Larger lesions or so called giant hemangiomas $(>5 \mathrm{~cm})$, also show a peripheral nodular enhancement and centripetal fill-in, but can have a persistent central hypointensity due to central fibrosis or thrombosis (Type III) $)^{33}$. Type 2 and type 3 enhancement pattern were present in our study.

Diffusion restriction and ring enhancement are noted in pyogenic liver abscess. Muller et al. first reported in 1994 on diffusion-weighted MRI of normal hepatic, splenic, and muscular tissues, as well as on focal and diffuse hepatic diseases, and obtained significant results

CEMRI is very sensitive and specific in detecting and differentiating regenerating nodules and dysplastic nodules in patients with cirrhosis liver. $\mathrm{T} 1 \mathrm{~W}, \mathrm{~T} 2 \mathrm{~W}$ and CEMRI is very specific for identifying these lesions.

\section{BIOPSY FINDINGS}

In our study FNAC/ biopsy findings played a supportive and confirmatory role in characterizing the lesions especially in patients with liver metastasis , HCC, liver abscess and

biliary cystadenoma

USG guided puncture of the simple cyst was done in one patient whom clear and haemorrhagic fluid was aspirated. The diagnosis was confirmed.

Metastasis: US guided FNAC was done from the liver lesion- proved to be metastatic in 7 cases and one case was multicentric HCC.

Pyogenic liver abscess: US guided aspiration was done showed pus and no complications was encountered.

USG guided FNAC was done in all cases of HCC and HPR came positive for 5 cases and one case was metastasis.

\section{FOLLOW UP STUDY}

Follow up was done in most of the patients with benign lesions like simple liver cysts, hemangiomas and abscess.

Simple liver cysts: follow up USG was done which confirmed the earlier diagnosis.

Liver abscess and hydatid cyst: patients responded to the specific therapy.

Hemangioma: follow up USG was done in all patients. All confirmed the earlier diagnosis and no increase in size.

\section{CONCLUSION}

The value of contrast enhanced MRI in the evaluation of focal hepatic neoplasm is proved in this study. It is safe, lacks ionizing radiation and is highly sensitive and specific.

Characterisation of focal liver lesion is very limited in ultrasound, which is the most 
commonly employed as a screening modality, mainly for lesion detection in the majority of cases.

Contrast CT one time used widely for lesion characterisation has got limitation as in detecting lesions like early HCC, regenerative and dysplastic nodules in patients with cirrhosis liver.

Considering commonest focal liver lesion hemangioma, even though CT shows characteristic enhancement pattern, MR has added advantage of heavily T2W signal characteristic which was proved in this study.

Considering hepatoma, the signal characteristics in dynamic $\mathrm{T} 1 \mathrm{~W}$ sequences is the stand-alone sequences for the diagnosis, also proved in this study.

Various enhancement pattern for the diagnosis of metastasis are also proved.

Hence apart from the routine TIW and T2W sequences, comprehensive imaging with heavily T2W sequence, contrat enhanced dynamic scanning and diffusion imaging help to characterise focal hepatic lesions.

\section{BIBLIOGRAPHY}

1. Schneck CD Embryology histology gross anatomy of the liver In Friedman A Dachman 1994 .Radiology of the liver

2. 19.Michaels NA : Newer Anatomy of the liver and its variant blood supply and collateral circulation. Am J Surg. 112 :337 $-347,1996$

3. Sexton CC,Zeman RK:Correlation of Computed Tomography,Sonography and gross anatomy of the liver.AJR 141 :711 718,1983

4. Ksales CJ,Patel S, Hopper KD; Imaging variants of the liver,pancreas and spleen.Crit Rev Diagn Imaging 35:485543,1994

5. Lee Joseph KT., Sagel S.S. Stanley RJ. et al. Text book of Computed Body Tomography with MRI Correlation. Third Edition: Vol. 1: 1998: 701 - 707.
6. Rumack C.M., Wilson S.R. Charbonneau J.W., Textbook of Diagnostic Ultrasound.. $2^{\text {nd }}$ Edition.St.Louis: CV Mosby,1998 pp95-96

7. RJ. Machell and RY. Calne: Solitary nonparasitic hepatic cyst presenting with jaundice. BJR51 :631-632,1978.

8. Dewburyk; Meire H; Cosgrove D. et al. Clinical Ultrasound A Comprehensive Text. Second Edition. Vol. 1, 2001 : 165231.

9. DuvnjakM, Supanc V, Virovic L, et al. Caroli's disease. Acta Med Croatica2003; 57: 249-252.

10. MathieuD, Vilgrain V, Mahfouz A, et al. Benign liver tumors. Magn Reson Imaging Clin N Am1997; 5: 255-288.

11. ZanggerP, Grossholz M, Mentha G, et al. MRI findings in Caroli's disease and intrahepatic pigmented calculi. Abdom Imaging 1995; 20: 361-364.

12. MercadierM, Chigot JP, Clot JP, et al. Caroli's disease. World J Surg1984; 8: 22-29.

13. AsselahT, Ernst O, Sergent G, et al. Caroli's disease: a magnetic resonance cholangiopancreatography diagnosis. Am J Gastroenterol1998; 93: 109-110.

14. GovilS, Justus A, Korah I, et al. Choledochal cysts: evaluation with MR cholangiography. Abdom Imaging1998; 23: 616-619.

15. PavoneP, Laghi A, Catalano C, et al. Caroli's disease: evaluation with MR cholangiopancreatography. AJR Am J Roentgenol1996; 166: 216-217.

16. Kadoya M,Matsui O, Nakanuma Y, et al; Ciliated hepatic foregut cysts: 11 Radiologic features. Radiology 175:475477,1990

17. Shoenut JP, Semelka RC, Levi C, Greenberg $\mathrm{H}$ : Ciliated hepatic foregut cysts:US,CT and contrast enhanced MR imaging. Abdom imaging 19:150152,1994 
18. Balci NC, Tunaci A, Semelka RC, et al: Hepatic alveolar ecchinococcosis: MRI findings. Magn Reson Imaging 18:537541,2000

19. WarshauerDM, Lee JK. Imaging manifestations of abdominal sarcoidosis. AJR Am J Roentgenol2004; 182: 15-28.

20. LehmuskallioE, Hannuksela M, Halme H. The liver in sarcoidosis. Acta Med Scand1977; 202: 289-293.

21. KlatskinG. Hepatic granulomata: problems in interpretation. Ann N Y Acad Sci1976; 278: 427-432.

22. KesslerA, Mitchell DG, Israel HL, et al. Hepatic and splenic sarcoidosis: ultrasound and MR imaging. Abdom Imaging1993; 18: 159-163.

23. WarshauerDM, Molina PL, Hamman SM, et al. Nodular sarcoidosis of the liver and spleen: analysis of 32 cases. Radiology1995; 195: 757-762.

24. BalciNC, Sirvanci M. MR imaging of infective liver lesions. Magn Reson Imaging Clin N Am2002; 10: 121-135.

25. RallsPW. Inflammatory disease of the liver. Clin Liver Dis2002; 6: 203-225.

26. RallsPW. Focal inflammatory disease of the liver. Radiol Clin North Am1998; 36: 377-389.

27. BakerRD. Histoplasmosis in routine autopsies. Am J Clin Pathol1964; 41: 457470.

28. AllaireGS, Rabin L, Ishak KG, Sesterhenn IA. Bile duct adenoma: a study of 152 cases. Am J Surg Pathol1988; 12:708-715.

29. Semelka RC, Hussain SM, Marcos HB, Woosley JT. Biliaryhamartomas: solitary an multiple lesions shown on current MR techniques including gadolinium enhancement. J. Magn. Reson. Imaging 1999; 10: 196-201 417,1993.

30. Li KC,Glazer GM,Quinr LE, et al: Distinction of hepatic cavernous hemangioma from hepatic metastasis with
MR imaging. Radiology 169:409415,1998

31. Lombardo DM,Baker ME, Spritzer CE,et al:Hepatic hemangiomas vs metastasis: MR differentiation at 1.5 T.Am J Roentgenol155:55-59,1990.

32. Danet IM, Samelka RC,Braga L,et al: Giant hemangioma of the liver: MR imaging characteristics in 24 patients. Magn Reson Imaging 21:95-101,2003.

33. Selbi DM,Stoker JT,Waclawiw MA, et al: Infantile hemangioendothelioma of liver. Hepatology 20(I Pt 1): 39-45,1994.

34. Chen CC, Kong MS, Yang CP, Hung IJ: Hepatic hemangioendothelioma in children: analysis of thirteen cases.Acta Paediatr Taiwan 44:8-13, 2003.

35. Mortele KJ, Vanzieleghem B, Mortele B,et al: Solitary hepatic infantile hemangioendothelioma : dyanamic gadolinium enhanced MR imaging findings. Eur Radiol 12 862-865,2002.

36. Schneider G, Grazioli L, Saini S: Imaging of benign focal liver lesions. In Schneider G, Grazioli L, Saini S(eds): MRI of the Liver. New York: Springer, 2003,pp 144145.

37. Shortell CK, Schwartz SI. Hepatic adenoma and focalnodular hyperplasia. Surg. Gynecol. Obstet. 1991; 173:426-31.

38. Mortelé KJ, Praet M, Vlierberghe HV, Kunnen M, RosPR. CT and MR imaging findings in focal nodular hyperplasiaof the liver: radiologic- Pathologic correlation. AJR2000; 175: 687-92.

39. Robbins: Pathologic Basis of Disease, V Edition

40. Shortell CK, Schwartz SI. Hepatic adenoma and focalnodular hyperplasia. Surg. Gynecol. Obstet. 1991; 173:426-31.

41. Paulson EK, McClellan JS, Washington K, Spritzer CE,Meyers WC, Baker ME. Hepatic adenoma: MR characteristicsand correlation with pathologic findings. Am. J.Roentgenol. 1994; 163: 113-16. 
42. Martin DR, Semelka RC. Imaging of benign and malignantfocal liver lesions. MRI Clin. N. Am. 2001; 9: 785-802.

43. Nonomura A, Mizukami Y Cadoya M: Angimyolipoma of liver: a collective review.J Gastro enterol 29: 95-105,1994.

44. Worawattanakul S, Kelekis NL,Semelka RC, Woosley JT:Hepatic angiomyolipoma with minimal fat content ; MR demonstration. Magn Reson Imaging 14:687-689,1996.

45. HortonKM, Bluemke DA, Hruban RH, et al. CT and MR imaging of benign hepatic and biliary tumors. RadioGraphics1999; 19: 431-451.

46. Wong Y,Chen F, Tai KS, et al: Imaging features of focal intrahepatic extramedullary haematopoeisis. $\mathrm{Br} \quad \mathrm{J}$ Radiol72:906-910,1999.

47. Warshauer DM, Schiebler ML; Intrahepatic extramedullary haematopoeisis; MR, CT, and sonographic appearance. J Compur Assist Tomogr 15:683-685,1991.

48. MorteléKJ, Ros PR. Cystic focal liver lesions in the adult: differential CT and MR imaging features. RadioGraphics2001; 21: 895-910.

49. Abraham H. Dachman et al : Nodular Regenerative Hyperplasia of the Liver: AJR V01.148:717-722, 1987

50. Dehner LP, Ewing SL, Summer HW: Infantile mesenchymal hamartoma of the liver. Histologic and ultrastructural observations. Arch Pathol1:245-267,1983.

51. Stocker JT, Ishak KG : Mesenchymal hamartoma of the liver: report of 30 cases and review of the literature. Paediatr Pathol 1:245-267, 1983.

52. Molina EG, Schiff ER: Benign solid lesions of the liver. In SCHIFF er,Sorell MF, Maddrey WC (eds): Diseases of the
Liver ( $8^{\text {th }}$ ed). Philadelphia: Lippincott Williams, 1999, pp 1245-1268.

53. Ros PR, Goodman ZD, Ishak KG, et al: Mesenchymal hamartoma of the liver: radiologic-pathologic correlation. Radiology 158:619-624, 1986.

54. O’Neil J, Ros PR: Knowing hepatic pathology aids MRI of liver tumors. Diagn Imaging 19:58-67, 1989

55. Danet IM, Semelka RC, Leonardou P et al. Spectrum ofMRI appearances of untreated metastases of the liver. Am.J. Roentgenol. 2003; 181: 809-17.

56. Hamm B, Thoeni RF, Gould RG et al. Focal liver lesions:characterization with nonenhanced and dynamic contrast-aterialenhanced MR imaging. Radiology 1994; 190:417-23. 